\title{
Status and Prospects of Concentrated Organic Wastewater Degradation
}

\author{
Wei Liu ${ }^{1,2}$, Dushu Huang ${ }^{1,2}$, Ping Yij ${ }^{1,2}$, Ying Li ${ }^{1}$ \\ ${ }^{1}$ College of Science, Honghe University, \\ ${ }^{2}$ Key Laboratory of Natural Pharmaceutical and Chemical Biology of Yunnan Province,
}

China

\section{Introduction}

Clean fresh water is essential to our life. Unfortunately, in our consumer-based economy, a large amounts of wastewater having been generated by industrial plants. Wastewaters produced in many industrial plants often contain organic compounds which are toxic and not amenable to direct biological treatment. These wastewaters must be treated in order to meet the specifications for discharge or for recycling in the process. Processes that enable the recycling of industrial wastewaters are becoming increasingly important as the amount and quality of freshwater available in certain regions of the world continues to decrease due to long periods of drought and growing water demands. In addition, increasingly stricter wastewater discharge standards continue to be introduced worldwide in an effort to reduce the environmental impacts of industrial processes. This has led to an increasing amount of research being conducted on processes for removing organic and inorganic pollutants from wastewaters.

Currently, biological and chemical methods are almost used to degrade the industrial organic wastewater. The biological methods can not achieve the desired results in most situations because most organic waste is toxic and difficult to degrade. For example, the toxic aqueous phenol solutions with concentrations exceeding $0.5 \mathrm{~g} / \mathrm{L}$ should not be treated in biological plants, even though laboratory tests have performed degradation of solutions with up to $2 \mathrm{~g} / \mathrm{L}$ of phenol (Foster, 1985). The incapability of conventional methods to effectively remove organic pollutants has made it evident that new, compact and more efficient methods with low energetic and operation costs are needed.

The chemical methods include wet oxidation processes, photocatalytic oxidation, sonochemical degradation technique and electrochemical oxidation technique. These alternative methods are the so-called advanced oxidation processes which have been reported to be effective for degradation of organic contaminants from wastewater. They are based on the initial formation of radicals such as hydroxyl radicals that later act as nonselective oxidation agents (Glaze, 1994; Ledakowicz, 1998; Scott \& Ollis, 1995). These methods are limited to treat waters which contain low concentrations of organic substances, and they are almost used in acidic, neutral or weak basic industrial organic wastewater treatment but not basic especially strong basic organic wastewater. 


\section{Wet oxidation and catalytic wet oxidation}

Wet oxidation (WO) which includes wet oxidation and catalytic wet oxidation (CWO), wet air oxidation (WAO) and catalytic wet air oxidation (CWAO) and catalytic wet peroxide (CWPO) can be distinguished in the oxidation processes which are carried out at high temperature and pressure conditions. Among the chemical methods of organic wastewater degradation, CWO is considered most prospective to achieve large-scale industrialization in a short time. WO and CWO processes that are used for removing vast variety of organic compounds from solution have been the subjects of considerable studies over the last six decades as numerous researchers continue to investigate the ability of these processes to remove different types of organic compounds from a wide variety of simple and complex wastewaters.

\subsection{Fundamentals of WO and CWO}

The WO oxidation process, which was first patented by Zimmerman in the late 1950s (Zimmerman, 1950), removes organic compounds in the liquid phase by oxidizing them completely using an oxidant such as oxygen or air. The process is extremely clean because it does not involve any harmful chemical reagents and the final products are carbon dioxide and water. However, one of the significant drawbacks of the WO process is that high temperatures and pressures are usually required to achieve a high degree of oxidation of many organic compounds within a reasonable amount of time.

Solution $\mathrm{pH}$ can influence WO process if a carboxylic acid and its corresponding salt have significantly different chemical stabilities. The difference in WO between acetic acid and the sodium salt of acetic acid is an example. In the research of Mishra (Mishra et al. 1995), the resonance stabilization energy makes the sodium salt more difficult to oxidize. The difference in WO process between oxalic acid and the sodium salt of oxalic acid can also be explained. Another possible effect that solution $\mathrm{pH}$ can have on the WO of some carboxylic acids involves the type of intermediates formed. In some cases, the solution $\mathrm{pH}$ can alter the reaction pathway of a carboxylic acid, leading to greater or lesser formation of certain intermediates.

The high temperatures, pressures, and reaction times usually required to achieve complete oxidation of organic compounds that are present in various wastewaters has led to a considerable amount of research on WO catalysts to overcome the costly, high-pressure, energy-intensive conditions. The number of different industrial waste streams requiring organics removal and the diversity of organic compounds has resulted in the investigation of a wide range of homogeneous and heterogeneous catalysts over the last three decades.

Catalytic wet oxidation (CWO) is an upgraded wet oxidation with the incorporation of suitable catalysts. It is a reaction involving an organic compound in water and oxygen over a catalyst and it can be used at much milder temperature and pressure conditions so that it can reduce the capital costs and the corrosion. Heterogeneous oxidation involves intensive contacting of an organic compound in solution with oxygen over a solid catalyst. Heterogeneous systems have the advantages over homogenous systems because the catalysts can be separated much more easily after the process (Luck, 1999; Matatov-Meytal \& Sheintuch, 1998; Mishra, 1995). The process of CWO and WO are considered to be very similar because acetic acid can be identified at the end of the reaction (Debellefontaine et al., 1996). 
The wet-air oxidation (WAO) process which generates active oxygen species such as hydroxyl radicals is also known to have a great potential for the treatment of wastewater containing a high content of organic compounds, for which traditional biological process is unfeasible (Mishra, 1995). The WAO process often takes place at high temperatures and pressures. In WAO processes, the organic contaminants dissolved in water are degraded by means of an oxidizing agent into biodegradable intermediates or inorganic compounds such as $\mathrm{CO}_{2}, \mathrm{H}_{2} \mathrm{O}$ and inorganic salts, which remain in the aqueous phase. One of the main drawbacks of the WAO process is its inability to achieve complete mineralization of organics. According to the WAO process, the organic compounds are oxidized in the liquid phase by some gaseous source of pure oxygen or air. Sulphur is converted to sulphate, halogens to halides and phosphorus to phosphates. Organic nitrogen may produce ammonia, nitrate and nitrogen. WAO produces no $\mathrm{NO}_{x}, \mathrm{SO}_{2}, \mathrm{HCl}$, dioxins, furans, fly ash, etc. Typical operating conditions are in the range of $100 \sim 300^{\circ} \mathrm{C}$ and $0.5 \sim 20 \mathrm{MPa}$. The main differences between the processes consist in the reactor type and the catalyst used.

Compared to conventional wet-air oxidation, catalytic wet-air oxidation (CWAO) has lower energy requirements (Alejandre et al., 2001; Lin et al., 2002; Silva et al., 2003; Bhargava et al., 2006). One can use less severe reaction conditions to reduce chemical oxygen and achieve much higher oxidation rates due to the presence of a catalyst. In the CWAO process, organics are oxidized to innocuous inorganic compounds such as $\mathrm{CO}_{2}, \mathrm{H}_{2} \mathrm{O}$ and heteroatom dissolved ions at much lower temperatures and pressures than in uncatalyzed processes. Interest in innovative methods of wastewater treatment based on catalytic oxidation has been growing rapidly, as this technique has been confirmed as a powerful method of purifying wastewaters in numerous studies (Silva et al., 2003; Abecassis-Wolfovich et al., 2004; Garcia et al., 2006; Gomes et al., 2005; Minh et al., 2006). The catalysts that have been used in CWAO include metal oxides, supported noble metals and active carbon. The metal oxides such as $\mathrm{CuO}, \mathrm{ZnO}, \mathrm{CoO}, \mathrm{Al}_{2} \mathrm{O}_{3}, \mathrm{MnO}$ and $\mathrm{CeO}$ etc. are all be used for aqueous effluents oxidation (Pintar \& Levec, 1994; Hamoudi et al., 1998; Chen et al., 2001; Pintar \& Levec, 1992). The noble metals of $\mathrm{Pd}, \mathrm{Pt}$, Ru and Ir have been very effective in the treatment of various compound, and the deposition of noble metals on hydrophobic supports such as active carbons and styrene divinyl benzene co-polymer, is also effective for oxidation of pollutants such as ammonia (Kim \& Ihm, 2002; Barbier et al., 2002; Pintar et al., 2001; Huang et al., 2001).

Wet peroxide oxidation (WPO) was proposed to use hydrogen peroxide as the oxidizer instead of molecular oxygen. As opposed to WAO-WO, which employ a gaseous source of oxidizing agent and which is a two-step process including mass transfer and oxidation, WPO uses a liquid oxidizing agent of hydrogen peroxide which eliminates the mass transfer problems. The reports about the WPO are scare, but its good efficiency lately proved has attracted attention. It has been proved to be effective under mild conditions for the treatment of phenolic compounds. The promising results about the degradation of phenolic compounds over several catalysts, such as iron aluminium combinations and Fe-Zeolites respectively have been obtained (Debellefontaine et al., 1996; García-Molina et al., 2006; Okawa et al., 2005; Najjar et al., 2005; Nikolopoulus et al., 2006).

\subsection{Application of WO and CWO}

There are many kinds of wastewater generated in chemical industries, such as pulp mill wastewater, dyeing and printing industrial wastewater, distillery wastewater, coking process wastewater and wastewater of paper mill and leather industries. 
The pulp wastewater contains the phenols and other organic compounds such as chloro-, thio-, and alkali-lignin. These compounds are resistant to biological degradation. Prasad (Prasad \& Joshi, 1987) studied the CWO of black liquor from the Kraft pulp industry, which is traditionally treated by incineration with cupric and zinc oxides, as well as manganese and selenium dioxides as catalysts. Sonnen et al. (Sonnen et al., 1997) found that the addition of transition metals to the reaction mixture can alleviate the formation of refractory compounds without compromising the rate of COD removal. An et al. found that aluminasupported palladium catalysts were very effective in removing pollutants and color from a Kraft pulp mill (An et al., 2001).

Wastewater from the dyeing and textile industries causes environmental problems because of the high COD loading and the color of these wastes. The color of these wastes is often strong enough to adversely affect the transmission of light, and the high COD loading depletes the oxygen content of the waterway, thus destroying marine life and the fragile ecosystems in waterways. WO has been used to these wastes. Lei et al. studied five different types of wet oxidative processes: WAO, CWAO, promoted CWAO, WPO and catalytic wet peroxide oxidation (CWPO) (Lei et al., 1998). Oxygen in excess is used for the first three of these processes, whereas no oxygen is required in the latter two. Chen et al. found that WAO and CWAO process which using $\mathrm{Cu}^{2+}$ ions could not be applied successfully to highconcentration reactive dyes at $200^{\circ} \mathrm{C} . \mathrm{H}_{2} \mathrm{O}_{2}$ was used as a promoter at a lower temperature of $150^{\circ} \mathrm{C}$ in order to improve COD reductions (Chen et al., 1999). Raffainer and van Rohr used promoted WO to the catalytic destruction of Orange II which is a representative contaminant from dyeing industries (Raffainer \& van Rohr, 2001). This process using $\mathrm{Fe}^{2+}$ ions at mild temperatures gave promising results. WO at a partial oxygen pressure of $1 \mathrm{MPa}$, a temperature of $190^{\circ} \mathrm{C}$, and a $\mathrm{pH}$ of 2 showed complete conversion of the dye in just an hour.

The process of converting biomass to ethanol produces wastewater, known as stillage, which is highly loaded with oxygen-demanding materials. Belkacemi et al. evaluated three different methods such as thermolysis, noncatalytic WO and CWO for the degradation of organics (Belkacemi et al., 1999). Dhale et al. selected wet oxidative treatment after the waste was treated by a thermal membrane pretreatment process (Dhale \& Mahajani, 2000). The pretreatment, which reduced the COD by $40 \%$ and the color by $30 \%$, was then followed by WO at $180-225^{\circ} \mathrm{C}$ and $\mathrm{PO}_{2} 0.69-1.38 \mathrm{MPa}$. A homogeneous $\mathrm{FeSO}_{4}$ catalyst at $210^{\circ} \mathrm{C}$ reduced the COD by $60 \%$ within $2 \mathrm{~h}$ and removed $95 \%$ of the color. This is only a slight improvement over noncatalytic wet oxidation, which achieved the same result at $220{ }^{\circ} \mathrm{C}$.

Leather-processing plants are required to evaluate their wastewater and reduce the concentration of toxic compounds. Wastewater from leather production contains high concentrations of inorganic and organic pollutants, which are usually removed by a combination of physical separation and WAO methods. Comadran et al. studied the deodorization and decolorization of wastewater from the leather and hide industries. A heterogeneous catalytic system was used in a single-stage process to effectively destroy odors caused by volatile organic compounds (Comadran \& Comella, 2002 ).

\subsection{Mechanism of degradation reactions}

In most systems, both $\mathrm{WO}$ and CWO occur simultaneously and reaction pathways are usually very similar. In this section, the chemistry of reaction kinetics and the types of chemical reactions that can lead to oxidation of various organic compounds are discussed. 


\subsubsection{Free-radical and non-free-radical reactions of WO process}

In WO process, in order to improve the rates of the chemical reactions, a better understanding of the types of reactions is required. The general consensus among researchers in the field is that the chemical reaction occurs mostly via free-radical chemical reactions. Once the radicals are generated, they virtually attack all organic compounds. According to the nature of the organic compounds, two types of initial attack are possible. One is that the radical abstracts a hydrogen atom to form water as with alkanes or alcohols. The other one possibility consists of an electrophylic addition of the radical to double bonds. After the addition of the radical, free organic radicals are generated that react with oxygen molecules generating a peroxiradical and allowing the initiation of a chain reaction system that ends in the complete mineralization of the compounds (Buxton et al., 1988; Glaze \& Kang, 1989; Haag \& Yao, 1992). Some examples of the different types of free-radical chemical reactions that can occur are showed by Eqs. 1-26 (Mantzavinos et al., 1997; Ingale et al., 1996; Robert et al., 2002; Rivas et al., 1998; Emanuel et al., 1980; Wakabayashi \& Okuwaki, 1988; Eyer, 2001; Li et al., 1991; Farhataziz \& Ross, 1977; Patterson et al., 2001; Glaze et al., 1995; Ichinose, S.; Okuwaki, 1990 ):

$$
\begin{aligned}
& \mathrm{RH}+\mathrm{O}_{2} \rightarrow \mathrm{R} \bullet+\mathrm{HO}_{2} \bullet \\
& \mathrm{H}_{2} \mathrm{O}+\mathrm{O}_{2} \rightarrow \mathrm{H}_{2} \mathrm{O}_{2}+\mathrm{O} \bullet \\
& \mathrm{H}_{2} \mathrm{O}+\mathrm{O}_{2} \rightarrow \mathrm{HO}_{2} \bullet+\bullet \mathrm{OH} \\
& \mathrm{RH} \rightarrow \mathrm{R} \bullet+\mathrm{H} \bullet \\
& \mathrm{O}_{2} \rightarrow \mathrm{O} \bullet+\mathrm{O} \bullet \\
& \mathrm{H}_{2} \mathrm{O} \rightarrow \bullet \mathrm{OH}+\mathrm{H} \bullet \\
& \mathrm{RH}+\mathrm{O}_{2}+\mathrm{RH} \rightarrow 2 \mathrm{R} \bullet+\mathrm{H}_{2} \mathrm{O}_{2} \\
& \mathrm{XCH}_{2}^{-}+\mathrm{O}_{2} \rightarrow \mathrm{XCH}_{2} \bullet+\mathrm{O}_{2} \bullet \\
& \mathrm{C}_{6} \mathrm{H}_{5} \mathrm{O}^{-}+\mathrm{O}_{2} \rightarrow \mathrm{C}_{6} \mathrm{H}_{5} \mathrm{O} \bullet+\bullet \mathrm{O}_{2}^{-} \\
& \mathrm{O}_{2}+e^{-} \rightarrow \bullet \mathrm{O}_{2}^{-} \\
& \mathrm{R} \bullet+\mathrm{O}_{2} \rightarrow \mathrm{ROO} \bullet \\
& \mathrm{ROO} \bullet+\mathrm{RH} \rightarrow \mathrm{ROOH}+\mathrm{R} \bullet \\
& \mathrm{O} \bullet+\mathrm{H}_{2} \mathrm{O} \rightarrow \mathrm{HO} \bullet+\mathrm{HO} \bullet \\
& \mathrm{RH}+\mathrm{HO}_{2} \bullet \rightarrow \mathrm{R} \bullet+\mathrm{H}_{2} \mathrm{O}_{2} \\
& \mathrm{H} \bullet+\mathrm{H}_{2} \mathrm{O} \rightarrow \mathrm{HO} \bullet+\mathrm{H}_{2}
\end{aligned}
$$




$$
\begin{gathered}
\mathrm{ROOH} \rightarrow \mathrm{RO} \bullet+\mathrm{HO} \bullet \\
\mathrm{RH}+\mathrm{HO} \bullet \mathrm{R} \bullet+\mathrm{H}_{2} \mathrm{O} \\
\mathrm{XCH}_{2} \mathrm{OO} \bullet+\mathrm{XCH}_{2}^{-} \rightarrow \mathrm{XCH}_{2} \mathrm{OO}^{-}+\mathrm{XCH}_{2} \bullet \\
2 \mathrm{ROO} \bullet \rightarrow \mathrm{ROOR}+\mathrm{O}_{2} \\
2 \mathrm{HO}_{2} \bullet \rightarrow \mathrm{H}_{2} \mathrm{O}_{2}+\mathrm{O}_{2} \\
\mathrm{HO}_{2} \bullet+\mathrm{OH}^{\bullet} \rightarrow \mathrm{H}_{2} \mathrm{O}+\mathrm{O}_{2} \\
\mathrm{XCH}_{2} \mathrm{OO} \bullet+\mathrm{O}_{2} \bullet \rightarrow \mathrm{XCH}_{2}^{-}+2 \mathrm{O}_{2} \\
2 \mathrm{O}_{2} \bullet+\mathrm{H}_{2} \mathrm{O}^{-} \rightarrow \mathrm{HOO}^{-}+\mathrm{HO}^{-}+\mathrm{O}_{2} \\
\mathrm{HO}^{-}+\mathrm{CO}_{3}^{2-} \rightarrow{ }^{-} \mathrm{OH}^{-} \bullet \mathrm{CO}_{3}^{-} \\
\mathrm{O}_{2} \bullet+\bullet \mathrm{CO}_{3}^{-} \rightarrow \mathrm{O}_{2}+\mathrm{CO}_{3}^{2-} \\
\mathrm{HO} \bullet+\mathrm{HCO}_{3}^{-} \rightarrow \mathrm{H}_{2} \mathrm{O}^{-} \bullet \mathrm{CO}_{3}^{-} \\
\mathrm{ROO} \bullet+\mathrm{O}_{2} \bullet \rightarrow \mathrm{ROO}^{-}+\mathrm{O}_{2}
\end{gathered}
$$

The radical pathway is very complex and it involves three main type chemical reactions such as initiation, propagation, and termination. Eqs. 1-10 above-mentioned belong to the type of initiation, and Eqs. 11-17 the type of propagation, the residual equations belong to the type of termination.

Although the majority of chemical reactions that lead to oxidation of organic compounds during WO are free-radical reactions, there are various other reactions that can lead to oxidation of an organic compound under typical WO conditions. Examples include removal of an a-hydrogen from a carboxylic acid/salt by hydroxide (Eq. 27), removal of an alcoholic hydrogen from phenol (Eq. 28), and base-induced retro-aldol reaction of $\alpha-\beta$-hydroxyacids (Eq. 29).

$$
\begin{gathered}
\mathrm{XCH}_{3}+{ }^{-} \mathrm{OH} \rightarrow \mathrm{XCH}_{2}^{-}+\mathrm{H}_{2} \mathrm{O} \\
\mathrm{C}_{6} \mathrm{H}_{5} \mathrm{OH}+{ }^{-} \mathrm{OH} \rightarrow \mathrm{C}_{6} \mathrm{H}_{5} \mathrm{O}^{-}+\mathrm{H}_{2} \mathrm{O} \\
\mathrm{C}_{6} \mathrm{H}_{8} \mathrm{O}_{7}+{ }^{-} \mathrm{OH} \rightarrow \mathrm{CH}_{3} \mathrm{CO}_{2} \mathrm{H}+\mathrm{HO}_{2} \mathrm{CCOCH}_{2} \mathrm{CO}_{2} \mathrm{H}^{-} \mathrm{OH}
\end{gathered}
$$

\subsubsection{Degradation process of CWAO}

CWAO is divided into homogeneous and heterogeneous catalytic wet oxidation in industry (Bhargava et al., 2006; Kolaczkowski et al., 1999; Patria et al., 2004; Luck, 1996; Ishii et al., 
1997). Bayer Loprox (Kolaczkowski et al., 1999) and ATHOS (Patria et al., 2004) methods have been used in industry are belong to homogeneous catalytic wet oxidation, which have some shortcomings including high reaction temperature, high reaction pressure and difficult to recover the homogeneous catalysts. On the other hand, Nippon Shokubai (Kolaczkowski et al., 1999; Luck, 1996) and Osaka methods (Luck, 1996; Ishii et al., 1997) are belong to heterogeneous catalytic wet oxidation, which can overcome the shortcomings of heterogeneous catalytic wet oxidation, but the service time and the stability of the catalyst is still not perfect. Although the catalytic wet oxidation has practical applications in industry, it is difficult to be directly applied to the basic organic wastewater because the $\mathrm{HO}$ generated in the process can be captured by $\mathrm{OH}-\mathrm{CO}_{3}{ }^{2-}, \mathrm{HCO}_{3}^{-}$and the loss of oxidative capacity of $\mathrm{HO}$ can be achieved in the basic conditions.

$$
\begin{gathered}
\mathrm{HO} \bullet+\mathrm{CO}_{3}^{2-} \rightarrow{ }^{-} \mathrm{OH}+\bullet \mathrm{CO}_{3}^{-} \\
\mathrm{HO} \bullet+\mathrm{HCO}_{3}^{-} \rightarrow \mathrm{H}_{2} \mathrm{O}+\bullet \mathrm{CO}_{3}^{-} \\
\mathrm{HO} \bullet+\mathrm{OH}^{-} \rightarrow \mathrm{H}_{2} \mathrm{O}+\mathrm{O} \bullet- \\
2 \mathrm{HO} \bullet+\mathrm{CO}_{2}^{-} \rightarrow \mathrm{H}_{2} \mathrm{O}+\bullet \mathrm{CO}_{3}^{-}
\end{gathered}
$$

Eqs. 30-33 shows the probable process of hydroxyl radical captured. It can be seen from the figure that in alkaline conditions, $\mathrm{OH}^{-}, \mathrm{CO}_{3}{ }^{2-}$ and $\mathrm{HCO}_{3}{ }^{-}$can capture the $\mathrm{HO} \cdot$. It make the $\mathrm{HO} \cdot$ lost the ability to further oxidation of organic compounds, which is now the difficulty of CWO directly used for organic alkaline wastewater.

Wakabashi and Okuwaki found that the metal copper powder can be an effective catalyst for the degradation of sodium acetate at $250{ }^{\circ} \mathrm{C}$, and a plausible but not confirmed catalytic mechanism (see Eqs. 34-38) was proposed (Wakabayashi \& Okuwaki, 1988). They considered that the acetate first generated to $\mathrm{XCH}_{2}^{-}$, then through $\mathrm{XCH}_{2}$ ' and $\mathrm{XCH}_{2} \mathrm{OO}{ }^{-}$, $\mathrm{XCH}_{2} \mathrm{OO}^{-}$was generated in the reaction process under alkaline conditions, and $\mathrm{XCH}_{2} \mathrm{OO}^{-}$is prone to further oxidation of oxalate, and carbonate and bicarbonate were finally achieved.

Wakabayashi and Okuwaki also found that increasing the alkalinity resulted in an increase in sodium acetate oxidation, using an iron powder catalyst in a nickel reactor. The nickel reactor was determined to corrode under the experimental conditions here, and, hence, nickel oxide acted as a co-catalyst for the oxidation reaction. They proposed a base-catalyzed oxidation mechanism for the oxidation of acetate in the presence of iron powder and nickel oxide, where the rate of formation of nickel oxide seems to be one of the rate-determining steps. The effect of alkalinity on the CWO reaction mechanism proposed by Wakabayashi and Okuwaki is an example of an indirect effect on the CWO mechanism. In this mechanism, hydroxide is required to increase the rate of formation of an intermediate species with which the catalyst reacts.

$$
\begin{gathered}
\mathrm{XCH}_{3}+\mathrm{OH}^{-} \stackrel{\mathrm{K}}{\longrightarrow} \mathrm{XCH}_{2}^{-}+\mathrm{H}_{2} \mathrm{O} \\
\mathrm{XCH}_{2}^{-}+\mathrm{O}_{2} \stackrel{k(\mathrm{MeO})}{\longrightarrow} \mathrm{XCH}_{2} \bullet+\mathrm{O}_{2}^{-}
\end{gathered}
$$




$$
\begin{gathered}
\mathrm{XCH}_{2} \bullet+\mathrm{O}_{2} \rightarrow \mathrm{XCH}_{2} \mathrm{OO} \bullet \\
\mathrm{XCH}_{2} \mathrm{OO} \bullet+\mathrm{XCH}_{2}^{-} \rightarrow \mathrm{XCH}_{2} \mathrm{OO}^{-}+\mathrm{XCH}_{2} \bullet \\
\mathrm{XCH}_{2} \mathrm{OO} \bullet+\mathrm{O}_{2}^{-} \rightarrow \mathrm{XCH}_{2} \mathrm{OO}^{-}+\mathrm{O}_{2} \bullet
\end{gathered}
$$

CWAO has got its success in laboratory applications but not yet the industrial recognition met with non-catalytic WAO. The main reasons are that the homogeneous catalysts have to be removed in a subsequent step, while the heterogeneous catalysts have to maintain their activity for sufficiently long periods. Many types of CWAO processes including NS-LC process, Osaka gas process and Kurita process are used currently (Kolaczkowski et al, 1999; Luck, 1984; Debellefontaine, 2000). The NS-LC process uses a vertical monolith reactor with a $\mathrm{Pt}-\mathrm{Pd} / \mathrm{TiO}_{2}-\mathrm{ZrO}_{2}$ catalyst. The operating conditions are $220^{\circ} \mathrm{C}$ and $4 \mathrm{MPa}$. The Osaka gas process uses a mixture of precious and base metals on titania or zirconia-titania supports. Typical operating conditions are $250^{\circ} \mathrm{C}$ and $6.86 \mathrm{MPa}$. The Kurita process uses nitrite instead of oxygen, and a similar catalyst, becoming more effective at lower temperatures, around $170^{\circ} \mathrm{C}$. Surprisingly, the industrial applications of CWAO operate at temperatures and pressures that are not significantly lower than those encountered in WAO. In addition, they use expensive noble metal catalysts.

\subsubsection{Mass transfer mechanisms of the WO reaction}

The mass transfer mechanisms involved in WO process are schematically illustrated in Fig.1. The following steps are necessary:

1. Oxygen diffusion from gaseous to liquid phase. In this step the oxygen contained in the gaseous phase transport from the bulk of the gaseous phase to the interface with the liquid phase, and then transport crosses the Gaseous-Liquid boundary layers and diffusion into the bulk of the liquid phase. However, this interface offers certain resistance to be crossed and it is necessary to reduce the thickness of the boundary layer as much as possible. By keeping turbulence in the liquid phase the boundary layer becomes thinner and the oxygen mass transfer improves. Despite the efforts to increase the efficiency of this mechanism, it is usually the responsible for the physical resistance in the whole process.

2. Diffusion of organic compounds from solid to liquid phase. The organic compounds of the solid phase transport cross the Solid-Liquid interface and dissolve into the bulk of the liquid phase. Normally this step does not present an important resistance to the whole process in view of the fact that the high temperature provokes a fast diffusion and dissolution of the solids.

3. Organics degradation reaction. As be shown by step 3 in the figure, the organics from the solid degraded by the oxygen from the gaseous phase. This WO reaction takes place in the liquid phase. The rate of the reaction depends on many factors such as temperature, pressure and catalyst.

4. Desorption of gaseous products. The $\mathrm{CO}_{2}$ formed in the course of the reaction transport from the liquid phase to the gaseous phase. This step does not suppose an important resistance to the whole process, not withstanding the fact that high pressure conditions complicate the diffusion of the gas from one phase to the other. 


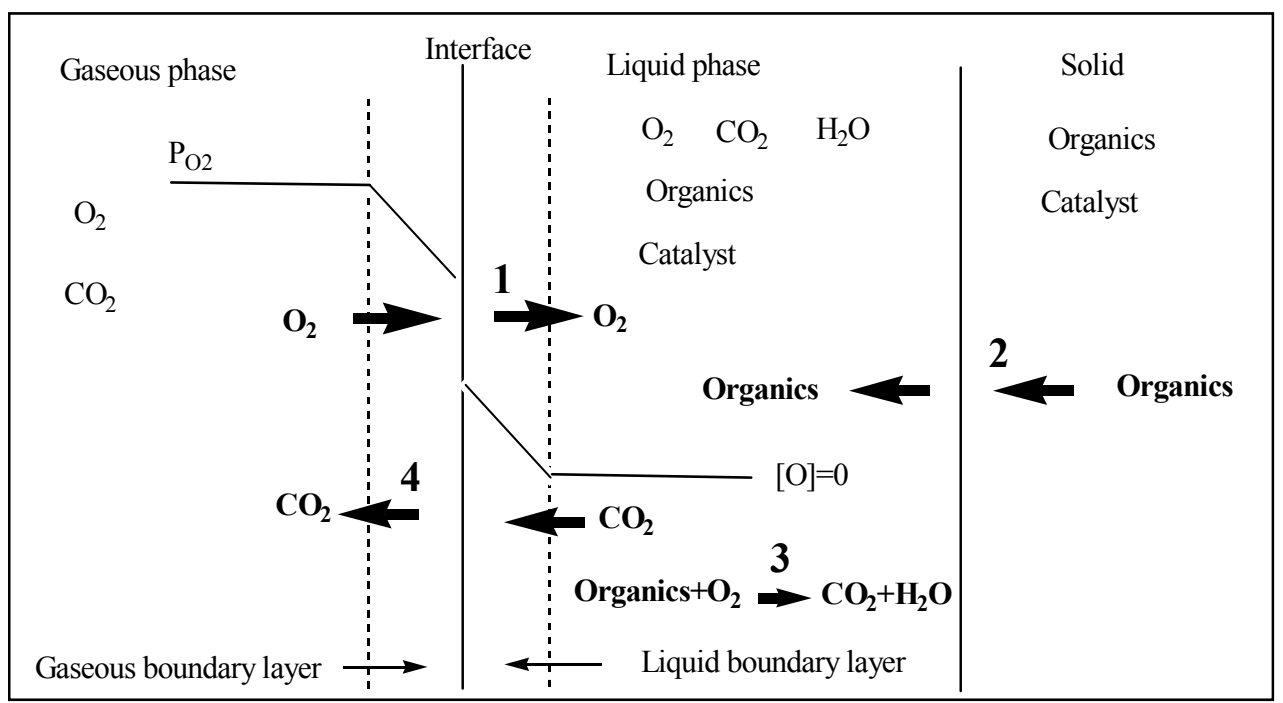

Fig. 1. Schematic representation of the mechanisms involved in wet oxidation processes

From the figure it can be observed that oxygen is transferred from the gaseous phase to the liquid phase (step 1), meanwhile organics diffuse from the solid phase to the liquid phase (step 2). The third step in the reaction mechanism is the oxidation of the organics by means of the oxygen (step 3). As a result of the reaction $\mathrm{CO}_{2}$ is formed which diffuses from the liquid phase to the gaseous phase (step 4).

Attending to the previous description of the mechanisms, it can be deduced that the controlling stages of the WO process are the diffusion of the oxygen from the gaseous phase and the chemical reaction. Three extreme cases are conceivable according to the rates of these mechanisms (Beyrich et al., 1979):

Case 1. The reaction rate is far higher than the diffusion rate of oxygen. The oxygen diffusing through the film is completely consumed in the film by a very rapid reaction. The rapid disappearance of the dissolved oxygen gives rise to a high concentration gradient at the interface of the gaseous phase and the liquid phase, and the oxygen is not present in the bulk of the liquid phase.

Case 2. The reaction rate is higher than the diffusion rate of oxygen. The reaction takes place essentially in the bulk of the liquid but the liquid dissolved oxygen concentration is low due to the reaction. So, the transfer of oxygen from the gaseous phase to the liquid phase controls the whole process.

Case 3. The reaction rate is far lower than the diffusion rate of oxygen. The reaction is so slow that the concentration of the dissolved gas in the bulk of the liquid attains approximately the interface concentration or even the saturation concentration. In this case, the reaction controls the whole process.

According to Beyrich (Beyrich et al., 1979), only the two last cases are of major importance for Wet Air Oxidation. 


\section{Photocatalysis oxidation}

Photocatalysis is generally thought of as the catalysis of a photochemical reaction at a solid surface, usually a semiconductor. The early photocehmical studies on aqueous solutions of organic wastewater in the presence of inorganic semiconductors such as silver halides, $\mathrm{ZnO}$, and the like were driven by applications in electro- and photography (Gerischer \& Willig, 1976; Memming, 1984). The first example for observing dye instability in the presence of an inorganic semiconductor $\left(\mathrm{TiO}_{2}\right)$ and illumination appears to be in 1969 when the photocatalytic reduction of Methylene blue to the leuco form was reported (Pamfilov et al., 1969; Yoneyama et al., 1972). This was rapidly followed by other studies. The photocatalytic oxidation of dyes such as Methylene Blue, Rhodamine B, Fluorescein and Methyl Orange was reported (Matthews, 1987, 1991). The early studies were accompanied soon by finding in many laboratories which showed that many organic compounds could be decomposed in aqueous media with a combination of $\mathrm{TiO}_{2}$ and near-UV light.

\subsection{Mechamisms of photocatalysis}

It is generally considered that photocatalysis is based in "back-to-back" or short-circuited photoelectrochemical and electrochemical reactions, involving electrogenerated electrons and holes. At the most global level, these can be written:

$$
\begin{gathered}
\mathrm{hv} \rightarrow \mathrm{e}_{\mathrm{CB}}^{-}+\mathrm{h}_{\mathrm{VB}}^{+} \\
2 \mathrm{H}_{2} \mathrm{O}+4 \mathrm{~h}^{+}{ }_{\mathrm{VB}} \rightarrow \mathrm{O}_{2}+4 \mathrm{H}^{+} \\
\mathrm{O}_{2}+4 \mathrm{H}^{+}+4 \mathrm{e}_{\mathrm{CB}}^{-} \rightarrow 2 \mathrm{H}_{2} \mathrm{O}
\end{gathered}
$$

Reactions (40) and (41) can be designated as the oxygen photoevolution reaction (OPER) and the oxygen reduction reaction (ORR), respectively. Of course, the later can occur either, as shown. On the titania surface itself or on a separate electrode. These processes can be examined sparately with standard electrochemical methods and can provide an overall rationale for the energetics. The point at which the anodic and cathodic currents are equal is a good indication of the local current that could be expected under a given set of conditions. The basic idea has been uesd for many years to quantitatively analyze the energetics of local electrochemical cells on corroding metals (Wagner et al, 1938, 2006).

Most of the organic pollutants in water can be completely decomposed and mineralized at the surface of UV-excited $\mathrm{TiO}_{2}$ photocatalysts; these include alkanes, haloalkanes, aliphatic alcohols, carboxylic acids, alkenes, aromatics, haloaromatics, polymers, surfactants, herbicides, pesticides, and dyes. While only UV light and $\mathrm{O}_{2}$ are necessary for the reactions, many factors such as light intensity, $\mathrm{PH}$, ions, photocatalysts, kinds and concentrations of substrateds, etc., have a great influence on the efficiency of the mineralization process. As in the gas-solod system, photocatalytic reactions in water work best at room temperature, and thus no heating is needed.

Serpone and co-workers studied the quantum yields of liquid-solid photocatalytic reations on $\mathrm{TiO}_{2}$ slurry photocatalysts (Salinaeo et al., 1999; Serpone \& Salinaro, 1999; Serpone 1997). Similarly to the study of Ohko et al., they found that maximum quantum yields could be 
obtained under light-limited conditions, that is, low light intensity and relative high substrate concentration (Emeline et al., 2005), The maximum QY (365 nm) for phenol degradation was measured as $14 \%$ using Degussa P25 as a photocatalyst at pH3, and this value varied over a range of $3.5 \%-30 \%$ for six types of $\mathrm{TiO}_{2}$ photocatalysts tested (Salinaeo et al., 1999; Serpone \& Salinaro, 1999). Aside from the light-limited condition, over a wide range of experimental conditions, liquid-solid photocatalytic reactions on $\mathrm{TiO}_{2}$ can also be described by the Eq. $\mathrm{r}=\mathrm{k} \Gamma \mathrm{I}^{\alpha}$, ( Here, $\mathrm{r}$ is the reaction rate, $\mathrm{k}$ the firt-order rate constant, $\Gamma$ the concentration per unit real surface area, and I the light intensity. Under light-rich conditions, the value of $\alpha$ is between 0 and 1), the same as for gas-solid photocatalytic reactions. The QYs measured in these conditions varied over the wide range of $0.1 \%-10 \%$, which was several times lower than those of gas-solod photocatalytic reactions. The low QY should restrict the applications of $\mathrm{TiO}_{2}$ photocatalysis in water purification. The intrinsic reasons for the lower QY in water vs. air are yet to be explained in detail.

Pichat et al. Studied the influence of the sintering process on the photocatalytic removal rate of various organic pollutants in water (Enriquea et al., 2007; Agrios \& Pichat, 2006; Enriquez et al., 2006). While the increase of sintering temperature is expected to decrease the recombination rate of charge carriers; it does result in a decrease in surface area. Their purpose was to examine the net effect of the sintering process on photocatalytic reactions. In one study, they compared the removal rate of three chlorophenolic compounds and one chloroaliphatic acid compound on four $\mathrm{TiO}_{2}$, samples, which were all obtained identically by $\mathrm{TiOSO}_{4}$ thermohydrolysis with subsequent calcinations at various temperatures (Enriquez et al., 2006). They found that the removal rate increased with the sintering temperatures for the three chlorophenolic compounds, whereas it was the opposite for the aliphatic acid compound. They suggested that the hole attack mechanism for carboxylic acids is much more sensitive to surface area variation than would be the $\bullet \mathrm{OH}$ radical mechanism for cholorophenolic compounds, which can react in the near-surface solution phase. Their studies demonstrate suggest the difficulty in finding a high-efficiency photocatalyst versatile for all types of pollutants in water(Enriquea et al., 2007).

Generally, loading of noble metal co-catalysts such as $\mathrm{Pt}, \mathrm{Au}$, and $\mathrm{Pd}$, etc., enables accelerating liquid-solid photocatalytic reactions (Sakthivel et al, 2004). These co-catalysts could enhance the charge separation and catalyze the oxygen reduction reaction. Recent studies suggest that addition of electron receptors, such as hydrogen peroxide, ozone, persulfate, etc., also works well for improving reaction rates (Kositai et al., 2004; Agustina et al, 2005). These electron receptors are more reducible than molecular oxygen. Moreover, when accepting an electron, these chemicals will dissociate into highly reactive radicals in subsequent reactions, which can also participate in the photocatalytic reactions (Akira, 2008).

$$
\begin{gathered}
\mathrm{H}_{2} \mathrm{O}_{2}+\mathrm{e}^{-} \rightarrow \mathrm{OH}^{-}+\bullet \mathrm{OH} \\
\mathrm{O}_{3}+\mathrm{e}^{-}+\mathrm{H}^{+} \rightarrow \mathrm{O}_{2}+\bullet \mathrm{OH} \\
\mathrm{S}_{2} \mathrm{O}_{8}^{2-}+\mathrm{e}^{-} \rightarrow \mathrm{SO}_{4}^{2-}+\mathrm{SO}_{4}^{-} \bullet
\end{gathered}
$$




\section{Sonochemical degradation}

Sonochemical processes have been widely used in chemistry and chemistry and chemical engineering field. Recently, these processes have found new applications in the environmental field, because of advantages in terms of operational simplicity, secondary pollutant formation and safety. Sonochemical treatment had been found to be one of the successful technologies for degradation of organic pollutants such as chlorinated aromatic and aliphatic compounds, phenolic compounds and dyes (Teo et al., 2001; Maleki et al., 2005; Vajnhandl \& Marechal, 2007).

\subsection{Basic principles of sonochemistry}

\subsubsection{Cavitation}

Sonochemistry is principally based on acoustic cavitation which includes the formation, growth, and implosive collapse of bubbles in a liquid. The diffuse energy of sound is enhanced through cavitation (Suslick, 1990). Positive and negative pressures are exerted on a liquid by compression and expansion cycles respectively of ultrasound waves (Suslick, 1989). When a sufficiently large negative pressure is applied to the liquid, the average distance between the molecules would exceed the critical molecular distance necessary to hold the liquid intact, and the liquid will break down and voids or cavities will be created; cavitation bubbles will then be formed (Mason \& Lorimer, 1988). The negative pressure works against the tensile strength of the liquid and thus it depends on the type and purity of the liquid. In pure water more than $1000 \mathrm{~atm}$ of negative pressure would be required for cavitation whereas in tap water, negative pressure of only a few atmospheres will form bubbles (Suslick, 1990). Once produced, these cavities, voids, or bubbles may grow in size until the maximum of the negative pressure has been reached (Mason \& Lorimer, 1988). The growth of cavitation bubble is mainly sound intensity dependent. Sometimes the cavity expansion occurs so quickly by high-intensity ultrasound during the negative-pressure cycle that the positive pressure in the next cycle cannot reduce the size of the cavity. For lowintensity ultrasound the size of the cavity oscillates in phase with the expansion and compression cycles and in this case the bubble surface area is comparatively larger during expansion cycles than during compression cycles. There is a critical size of cavitation bubble which depends on the ultrasound frequency and in this situation the cavity can absorb energy more efficiently from ultrasound and grow more rapidly. But when a cavity experiences a very rapid growth it can no longer absorb energy as efficiently from the sound waves and thus the liquid rushes in and the cavity implodes (Suslick, 1990). Gas and vapors are compressed inside the cavity and this generates heat, which finally produces a shortlived localized hot spot. In brief the cavitational collapse creates an unusual environment for a chemical reaction in terms of enormous local temperatures and pressures (Suslick, 1989). The most sophisticated models predict temperatures of thousands of degrees Celsius, pressures of from hundreds to thousands of atmospheres and heating times of less than a microsecond (Suslick, 1990).

\subsubsection{Sonochemical reaction schemes}

The sonochemical reactions differ from chemical reactions in many ways. The ultrasonic energy influences the chemical reactions by providing huge heat (pyrolysis) or producing 
reactive free radicals (Suslick, 1990). Again ultrasonic waves increase the mass transfer rate in an aqueous solution via turbulence (Gondrexon et al, 1997; Weavers \& Hoffmann, 1998). There are mainly three reaction sites (Fig.2): a) cavity interior; b) gas-liquid interface; and c) bulk liquid. Inside the cavitation bubble water molecules are pyrolyzed forming $\bullet \mathrm{OH}$ and - $\mathrm{H}$ radicals in the gas phase. The substrate either reacts with the hydroxyl radical or undergoes pyrolysis. In the interfacial region, a similar reaction occurs but in an aqueous phase. The additional reaction is the recombination of $\bullet \mathrm{OH}$ radicals to form $\mathrm{H}_{2} \mathrm{O}_{2}$. In bulk phase the reactions are basically between the substrate and the $\bullet \mathrm{OH}$ radical or $\mathrm{H}_{2} \mathrm{O}_{2}$. All these reactions are considered in homogeneous sonochemistry (Adewuyi, 2001). Most of the hydrophobic compounds react inside the cavitation bubble whereas hydrophilic substances react at bulk phase (Adewuyi, 2001; Liang et al., 2007). The heterogeneous systems also follow the same physical mechanism but differ in terms of cavitational threshold, high speed liquid jet etc. (Liang et al., 2007).

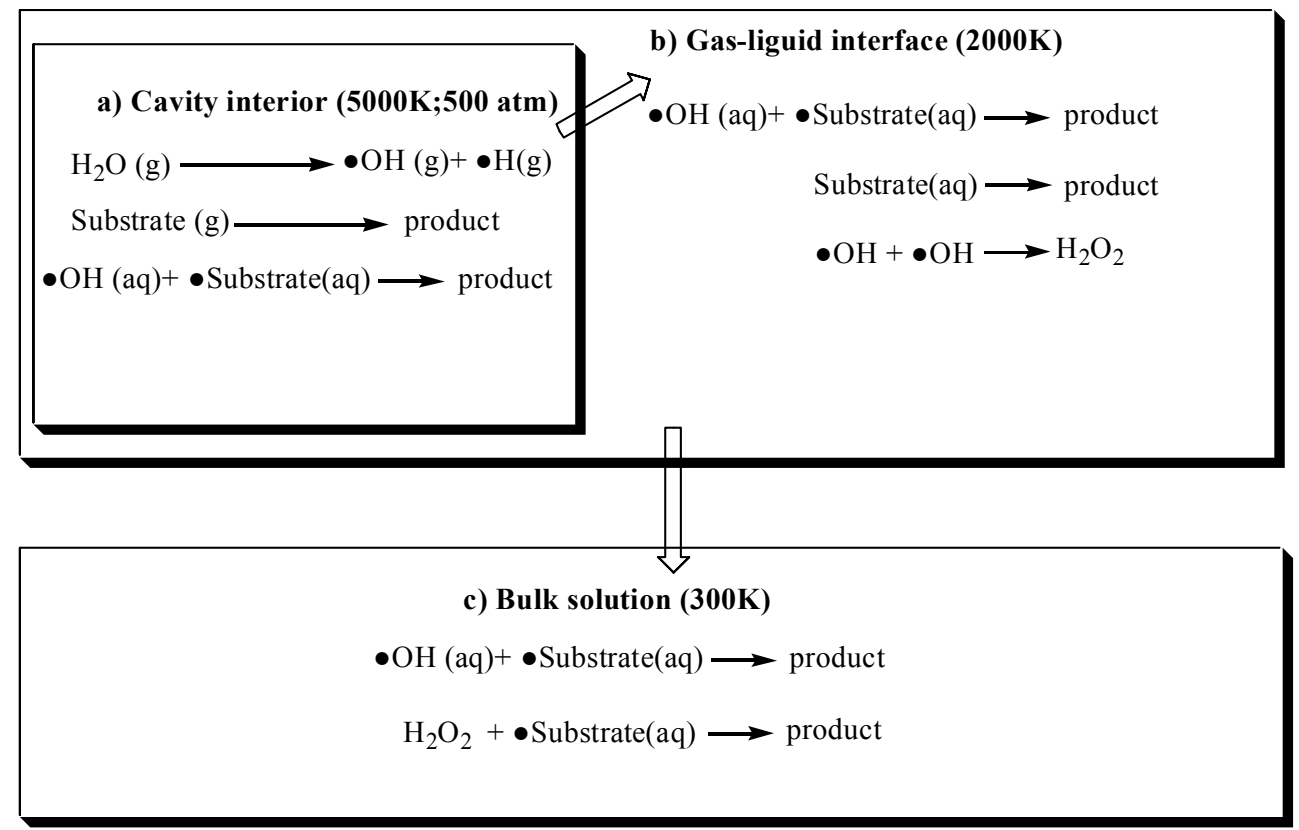

Fig. 2. Sonochemical reaction zones

The degradation of organic compounds mainly follows either thermal decomposition or free radical reaction mechanism. Inside a cavitation bubble only thermal decomposition (pyrolysis) occurs in gas phase with the rupture of $\mathrm{C}-\mathrm{C}, \mathrm{C}=\mathrm{C}, \mathrm{C}-\mathrm{N}, \mathrm{C}-\mathrm{O}$ bonds at a very high temperature $(\sim 5000 \mathrm{~K})$. At the gas-liquid interface both thermal decomposition $(\sim 2000$ $\mathrm{K})$ and free radical $(\mathrm{OH})$ reaction may occur side by side. The reaction mechanism is basically controlled by the physical properties of the organic compounds. Volatile and hydrophobic organic compounds are degraded mainly by direct thermal decomposition leading to formation of combustion byproducts whereas hydrophobic and less volatile or nonvolatile organic compounds degrade to form oxidation or reduction byproducts by 
reacting with $\bullet \mathrm{HO}$ radicals or hydrogen atoms diffusing out of the cavitation bubbles (Pankaj \& Viraraghavan, 2009).

Sonochemical degradation seems to be a promising technology for degradation of several organic compounds. The degradation process is governed by pyrolysis and/or free radical reactions. The extent of degradation depends on both ultrasonic (frequency, power) and experimental (temperature, $\mathrm{pH}$, dissolved gas) conditions. The substrate characteristics (vapor pressure, density, surface tension etc.) also influence sonochemical reactions. In terms of operation simplicity it is an acceptable treatment process but it is efficient with compounds possessing a high vapor pressure (e.g. $\mathrm{ClBz}_{1} \mathrm{CCl}_{4}$ ). Although the initial rate of sonolchemical degradation is fast, complete mineralization is not achieved in most cases. Sometimes it needs much higher energy for complete mineralization which is economically not favorable. Ultrasound can be used with other advanced oxidation processes in combination to provide a higher efficiency. Most of studies are laboratory oriented which cannot be implemented directly in large scale applications. More studies are needed on kinetics, reactor design and scale-up for practical application (Pankaj \& Viraraghavan, 2009).

\section{Electrochemical oxidation}

Electrochemistry, as a branch of physical chemistry plays an important role in most areas of science and technology (Grimm et al, 1998). Electrochemistry offers promising approaches for the prevention of pollution problems in the process industry. The inherent advantage is its environmental compatibility, due to the fact that it uses a clean reagent, the electron. The strategies include both the treatment of effluents and waste and the development of new processes or products with less harmful effects, often denoted as process-integrated environmental protection (Bockris, 1972).

Electrochemical technologies have gained importance in the world during the past two decades. There are different companies supplying facilities for metal recoveries, the treatment of drinking water as well as process waters resulting from tannery, electroplating, dairy, textile processing, oil and oil-in-water emulsion, etc. (Chen, 2004). At present, electrochemical technologies have reached such a state that they are not only comparable with other technologies in terms of cost, but sometimes they are more efficient and compact. The development, design and application of electrochemical technologies in water and wastewater treatment has been focused on particularly in some technologies such as electrodeposition, electrocoagulation, electrofloculation and electrooxidation (Rajeshwar, 1994).

Studies on electrochemical oxidation for wastewater treatment go back to the 20th century (Rajeshwar, 1994), when the electrochemical decomposition of cyanide was investigated (Kuhn, 1971). Extensive investigation of this technology commenced in the 70s, when Nilsson et al. In 1973 investigated the anodic oxidation of phenolic compounds (Nilsson, 1973). Mieluch et al. studied for the first time the electrochemical oxidation of phenol compounds in aqueous solutions (Mieluch, 1975). In 1975, Dabrowski et al. studied the electrochemical purification of phenol-containing wastes in a pilot plant (Dabrowski, 1975), while Papouchado et al. investigated the pathways of phenolic compounds anodic oxidation 
(Papouchado, 1975). Later, in 1979, Koile and Jonhson examined the electrochemical removal of phenolic films from platinum anodes (Koile \& Johnson, 1979); in the same period, Smith de Sucre obtained relevant results in phenol electro-oxidation during wastewater treatment (Smith, 1979), and in the 80s these studies were continued in collaboration with Chettiar(Chettia, 1981; Chettiar \& Watkinson, 1983).

During the last two decades, research work has focused on the efficiency in oxidizing various pollutants at different electrodes, on the improvement of the electrocatalytic activity and electrochemical stability of the electrode materials, the investigation of factors affecting the process performance and the exploration of mechanisms and kinetics of pollutant degradation (Chen, 2004). Experimental investigations, focusing on the behaviour of different anodic materials, have been carried out by different research groups, the results of which warrant a detailed description. Attempts for an electrochemical oxidation/destruction treatment for waste or wastewater can be subdivided into two important categories: direct oxidation at the anode, and indirect oxidation using appropriate anodically-formed oxidants (Juttner et al, 2000).

\subsection{Electrochemical oxidation mechanism}

Electrochemical oxidation of pollutants can occur directly at anodes through the generation of physically adsorbed "active oxygen" (adsorbed hydroxyl radicals, $\bullet \mathrm{OH}$ ) or chemisorbed "active oxygen" (oxygen in the oxide lattice, $\mathrm{MO}_{\mathrm{x}+1}$ ) (Comninellis, 1994). This process is usually called "anodic oxidation" or "direct oxidation" and the course for the anodic oxidation was described by Comninellis (Comninellis, 1994); the complete destruction of the organic substrate or its selective conversion into oxidation products is schematically represented in eq. $45^{-}$eq. 50 .

When a toxic, non-biocompatible pollutant is treated, the electrochemical conversion transforms the organic substrate into a variety of metabolites; often, biocompatible organics are generated, and biological treatment is still required after the electrochemical oxidation. In contrast, electrochemical degradation yields water and $\mathrm{CO}_{2}$, no further purification being necessary. Nevertheless, the feasibility of this process depends on three parameters: (1) the generation of chemically or physically adsorbed hydroxyl radicals, (2) the nature of the anodic material and (3) the process competition with the oxygen evolution reaction.

A mechanism for the electrochemical oxidation of organics, based on intermediates of oxygen evolution reaction in aqueous media, was formerly proposed by Johnson (Feng \& Johnson, 1990; Chang \& Johnson, 1990, 1990; Vitt \& Johnson, 1992; Feng et al, 1994; Treimer et al, 2001). The process involves anodic oxygen transfer from $\mathrm{H}_{2} \mathrm{O}$ to organics via hydroxyl radicals formed by water electrolysis.

The electrochemical oxidation of some organics in aqueous media may take place without any loss in electrode activity, except at high potentials, and with concomitant evolution of oxygen (Comninellis \& Nerini, 1995; Comninellis \& Plattner, 1998; Tahar \& Savall, 1998; Comninellis \& Battisti, 1996). Furthermore, it has been described that the nature of the electrode material strongly influences both the selectivity and the efficiency of the process (Comninellis, 1994; Comninellis \& Battisti, 1996; Foti et al, 1997; Simond, 1997). To interpret 
these observations, a comprehensive model for the anodic oxidation of organics in acidic medium, including the competition with the oxygen evolution reaction, has been proposed (Comninellis, 1994; Comninellis \& Battisti, 1996; Foti et al, 1997; Simond, 1997). More recent results, obtained at conductive diamond electrodes7 (which are characterized by a very high oxygen overpotential), fit the model predictions quite well. Based on these results, Comninellis explained the differences considering two limiting cases, i.e. the so-called "active" and "non-active" anodes (Marselli et al, 2003).

In both cases, the first reaction (eq. 45) is the oxidation of water molecules leading to the formation of adsorbed hydroxyl radicals:

$$
\mathrm{M}+\mathrm{H}_{2} \mathrm{O} \rightarrow \mathrm{M}(\mathrm{HO} \bullet)+\mathrm{H}^{+}+\mathrm{e}^{-}
$$

Both the electrochemical and chemical reactivities of adsorbed hydroxyl radicals depend strongly on the nature of the used electrode material.

With active electrodes there is a strong interaction between the electrode $(\mathrm{M})$ and the hydroxyl radical $(\bullet \mathrm{OH})$. Adsorbed hydroxyl radicals may interact with the anode, forming a socalled higher oxide MO (eq. 46). This may be the case when higher oxidation states are available, for the electrode material, above the thermo-dynamic potential for the oxygen evolution (1.23 V vs. SHE)[104].

$$
\mathrm{M}(\mathrm{HO} \bullet) \rightarrow \mathrm{MO}+\mathrm{H}^{+}+\mathrm{e}^{-}
$$

With active electrodes, the redox couple $\mathrm{MO} / \mathrm{M}$ acts as a mediator in the oxidation of organics (eq. 47). This reaction is in competition with the side reaction of oxygen evolution, which is due to the chemical decomposition of the higher oxide (eq. 48):

$$
\begin{gathered}
\mathrm{MO}+\mathrm{R} \rightarrow \mathrm{M}+\mathrm{RO} \\
\mathrm{MO} \rightarrow \mathrm{M}+\frac{1}{2} \mathrm{O}_{2}
\end{gathered}
$$

The oxidative reaction via the surface redox couple $\mathrm{MO} / \mathrm{M}$ (eq. 47) may be much more selective than the reaction involving hydroxyl radicals (eq. 49). A typical example of an active electrode is the case of $\mathrm{IrO}_{2}$ (Comninellis, 1994).

With a non-active electrode, weak interactions exist between the hydroxyl radical and the electrode surface. In this case, the oxidation of organics is mediated by hydroxyl radicals (eq. 49) and may result in fully oxidized reaction products such as $\mathrm{CO}_{2}$.

$$
\mathrm{M}(\mathrm{HO} \bullet)+\mathrm{R} \rightarrow \mathrm{M}+\mathrm{mCO}_{2}+\mathrm{nH}_{2} \mathrm{O}+\mathrm{H}^{+}+\mathrm{e}^{-}
$$

In the above schematic equation, $\mathrm{R}$ is a fraction of an organic compound containing no heteroatoms, which needs one oxygen atom to be fully transformed into $\mathrm{CO}_{2}$ (Marselli et al, 2003). This reaction competes with the side reaction of hydroxyl radicals (direct or indirect consumption, through the formation of hydrogen peroxide as intermediate) to oxygen (eq. 50) without any participation of the anode surface: 


$$
\mathrm{M}(\mathrm{HO} \bullet) \rightarrow \mathrm{M}+\frac{1}{2} \mathrm{O}_{2}+\mathrm{H}^{+}+\mathrm{e}^{-}
$$

A non-active electrode does not participate in the anodic reaction and does not provide any catalytic active site for the adsorption of reactants and/or products from the aqueous medium. In this case, the anode serves only as an inert substrate, which can act as a sink for the removal of electrons. In principle, only outer-sphere reactions and water oxidation are possible with this kind of anode. Intermediates produced by the water oxidation are subsequently involved in the oxidation of organics in aqueous medium (Marselli et al, 2003).

The electrochemical activity (which may be related to the overpotential for oxygen evolution) and chemical reactivity (rate of the organics oxidation with electrogenerated hydroxyl radicals) of adsorbed $\bullet \mathrm{OH}$ are strongly linked to the strength of the $\mathrm{M}-\mathrm{OH} \bullet$ interaction. As a general rule, the weaker the interaction, the higher the anode reactivity for organics oxidation (fast chemical reaction); boron-doped diamond electrodes (BDD) are typical non-active electrodes, characterized by high stability and acceptable conductivity. This model assumes that the electrochemical oxidation is mediated by hydroxyl radicals, either adsorbed at the surface (in the case of active electrodes) or free, in the case of the nonactive ones (Marselli et al, 2003; Carlos et al., 2006).

\section{Conclusion and outlook}

Three important aspects of WO and CWO process have been thoroughly reviewed: (i) the fundamentals of WO; (ii) the degradation of organic pollutants using WO process; and (iii) the mechanism of degradation reactions. WO and CWO studies on the wide range of industrial process waters and wastewaters illustrate the potential of these technologies. The potential benefits of the CWO process over other conventional water treatment processes, such as low reaction temperatures and residence times and the formation of harmless products, will be a key driver for more research in the field. The main challenge faced in the development of successful industrial-scale CWO processes for treating specific wastewaters seems to be the development of suitable catalysts which is highly active, economical, and environmentally friendly. It is anticipated that further research in the area of catalytic activity, combined with research on catalyst stability, reusability, and environmental friendliness, will lead to the discovery of catalysts that are effective for many industrial-scale CWO processes.

Some of the fascinating new applications of photocatalysis have been indicated. These are not to be considered so very separate from the fundamental work. Both tend to reinforce each other. We believe that people working in both fundamental and applied aspects should try very hard to understand what the others are doing. This will undoubtedly lead to advances in both areas.

The relative high estimated cost for ultrasound treatment can be reduced by developing better transducer technology and increasing the efficiency of electrical to acoustic energy conversion. Future studies can be directed towards the development of efficient transducers, reduction of energy loss in the ultrasonic system and the design of economically feasible full 
scale ultrasonic reactors. Ultrasound can be sued with other advanced oxidation processes in combination to provide a higher efficiency. Most of studies are laboratory oriented which cannot be implemented directly in large scale applications. More studies are needed on kinetics, reactor design and scale-up for practical application.

The analysis of available literature points out the validity of the electrochemical approach for the elimination of different organic pollutants; in consideration of the specific reactivity of each organic substrate, dedicated tests should be carried out in order to identify the most suitable electrode materials and experimental conditions. Generally speaking, the mediated electrochemical approach can be considered more effective than the direct one, because of the minor problems of electrode fouling and/or corrosion. In contrast with other technologies, the form of the waste (liquid, sludge) and its homogeneity are relatively unimportant: the CerOx approach is surely more appropriate in the case of a sludge, while Bakhir's modular plants are dedicated to clear water solutions when a direct oxidation is chosen, but the limitation disappears in case of a mediated approach.

\section{Acknowledgment}

This work was supported by the Research of National Quality Inspection standards of nonprofit industry (200810998)

\section{References}

Abecassis-Wolfovich, M., Landau, M.V., Brenner, A., Herskowitz, M. Ind.Eng. Chem. Res. 43 (2004) 5089.

Adewuyi Y. G., Ind Eng Chem Res 2001;40:4681-4715.

Agrios A.G., Pichat P., J. Photochem. Photobiol. A: Chem. 180 (2006) 130-135.

Agustina T. E., Ang H.M., Vareek V. K., J. Photochem. Photobiol. C: photochem. Rev. 6 (2005) 264-273.

Akira F., Xintong Z., T. Donald A., Surf. Sci. Rep. 63 (2008) 515-582.

Alejandre, A., Medina, F., Rodriguez, X., Salagre, P., Cesteros, Y. J.E.Sueiras, Appl. Catal. B 30 (2001) 195.

An, W.; Qinglin, Z.; Ma, Y.; Chuang, K. T. Catal. Today 64 (2001) 289.

Barbier Jr., J., Oliviero, L., Renard, B., Duprez, D. Catalysis Today 75 (2002) 29.

Belkacemi, K.; Larachi, F.; Hamoudi, S.; Turcotte, G.; Sayari, Ind. Eng. Chem. Res. 38(1999) 2268.

Beyrich, J., Gautschi, W., Regenass, W., Wiedmann, W. Comp. Chem. Eng. 3 (1979) 161.

Bhargava, S.K., Tardio, J., Prasad, J., Foger, K., Akolekar, D.B., Grocott, S.C. Ind. Eng. Chem. Res. 45 (2006) 1221.

Bockris J. O'M. Electrochemistry of cleaner environments, Plenum, New York, 1972.

Buxton, G.V., Greenstock, C.L., Helman, W.P., Ross, A.B. J. Phys. Chem. 17 (1988) 513.

Carlos A., Martı́nez H., Sergio F.. Chem. Soc. Rev. 2006 (35), 1324-1340

Chang H., Johnson D. C., J. Electrochem. Soc., 1990, 137, 2452-2457.

Chang H., Johnson D. C., J. Electrochem. Soc., 1990, 137, 3108-3113.

Chen, G.; Lei, L.; Yue, P.-L. Ind. Eng. Chem. Res. 38 (1999) 1837. 
Chen G., Sep. Purif. Technol., 2004, 38, 11-41.

Chen, H., Sayari, A., Adnot, A., Larachi, F. Appl. Cat. B: Environ. 32 (2001) 195.

Chettiar M., M.A. Sc. Thesis, University of British Columbia, (1981).

Chettiar M.,Watkinson A. P., Can. J. Chem. Eng., 1983, 61, 568-574.

Comadran, G.; Comella, J. Ing. Quim. 34 (2002) 135.

Comninellis Ch., Battisti A. De, J. Chim. Phys., 1996, 93, 673-679.

Comninellis Ch., Electrochem. Acta, 1994, 39, 1857-1862.

Comninellis Ch., Nerini A., J. Appl. Electrochem., 1995, 25, 23-28.

Comninellis Ch., Plattner E., Chimia, 1988, 42, 250-252.

Dabrowski A., Mieluch J., Sadkaoski A., Wild J., Zoltowski P., Prezm. Chem., 1975, 54, 653655.

Debellefontaine, H., Chakchouk, M., Foussard, J.N., Tissot, D., Striolo, P. Environmental Pollution 92 (2) (1996) 155.

Debellefontaine, H., Foussard, J.N. Waste Management 20(2000)2.

Dhale, A. D., Mahajani, V. V. Indian J. Chem. Technol. 7 (2000) 11.

Emanuel, N. M.; Zaikov, G. E.; Maitus, Z. K. Oxidation of Organic Compounds. Medium Effects in Radical Reactions; Pergamon Press: Oxford, U.K., 1980.

Emeline A.V., Ryabchuk V.K., Serpone N. J. Phys. Chem. B 109 (2005) 18515-18521.

Enriquea R. Agrios A. G., Pichat P., Catal. Today 120 (2007) 196-202.

Enriquez R., Pichat P., Environ J. Science Health A: 41 (2006) 955-966

Eyer, S. L. Investigation of Catalytic Wet Oxidation of Bayer Liquor, Ph.D. Dissertation, Department of Applied Chemistry, RMIT University, Melbourne, Australia, 2001.

Farhataziz, P. C.; Ross, A. B. Selected specific rates of radicals of transients from water in aqueous solutions. National Bureau of Standards, Washington, DC, NSDRS-NBS59, 1977.

Feng J., Johnson D. C.. J. Electrochem. Soc., 1990, 137, 507-510.

Feng J., Johnson D. C., Lowery S. N., Carey J.. J. Electrochem. Soc., 1994, 141, 2708-2711.

Foster, C.F. Biotechnology and wastewater treatment. Cambridge University Press, Cambrage, 1985

Foti G., Gandini D., Comninellis Ch., Curr. Top. Electrochem., 1997, 5, 71-91.

Garcia, J., Gomes, H.T., Serp, Ph., Kalck, Ph., Figueiredo, J.L., Faria, J.L. Carbon 44 (2006) 2384.

García-Molina, V., Esplugas, S., Wintgens, Th., Melin, Th. Desalination 189 (2006) 110.

Gerischer H., Willig F., Top. Vurr. Chem. 61(1976) 31.

Glaze, W. H. Chem. Oxid. 2 (1994) 44.

Glaze, W.H., Kang, J.W. Advanced oxidation processes. Ind. Eng. Chem. Res. 28 (1989) 1573.

Glaze, W. H.; Lay, Y.; Kang, Joon-Wun. Ind. Eng. Chem. Res. 34 (1995) 2314.

Gomes, H.T., Selvam, P., Dapurkar, S.E., Figueiredo, J.L., Faria, J.L. Micropor. Mesopor. Mater. 86 (2005) 287.

Gondrexon N., Renaudin V., Boldo P., Gonthier Y., Bernis A., Petrier C., Chem Eng J 1997;66:21-26.

Grimm J., Bessarabov D. , Sanderson R. D., Desalination, 1998, 115, 285-294.

Haag, W.R., Yao, C.C.D. Environ. Sci. Technol. 26 (1992) 1005. 
Hamoudi, S., Larachi, F., Cerrella, G., Cassanello, M. Ind. Eng. Chem. Res. 37 (1998) 3561.

Huang, T.-L., Maccines, J. M., Cliffe, K. R. Wat. Res. 35 (2001) 2113.

Ichinose, S.; Okuwaki, A. Bull. Chem. Soc. Jpn. 63(1990) 159.

Ingale, M. N.; Joshi, J. B.; Mahajani, V. V.; Gada. M. K. Process Safety EnViron. Protect. 74 (1996) 265.

Ishii, T., Mitsui, K., Sano, K., Shishida, K., Shiota,Y. Patent, U.S.5399541, 1997

Juttner K., Galla U., Schmieder H., Electrochim. Acta, 2000, 45, 2575-2594.

Kim, S-K., Ihm, S-K. Ind. Eng. Chem. Res. 41 (2002) 1967.

Koile R. C., Johnson D. C., Anal. Chem., 1979, 51, 741-744.

Kolaczkowski, S.T., Plucinski, P., Beltran, F.J., Rivas, F.J., Mclurgh, D.B. Chem.Eng.J. 73(1999) 143.

Kositai M., Antoniadis A. Poulios I., Kiridis I., Malato S., Solar Energy 77 (2004) 591-600.

Kuhn A., J. Appl. Chem. Biotechnol., 1971, 21, $29-64$.

Ledakowicz, S. Environ. Protect. Eng. 24 (1-2) (1998) 35.

Lei, L.; Hu, X.; Yue, P. Water Res. 32 (1998) 2753.

Liang J., Komarov S., Hayashi N., Kasai E.. Ultrason Sonochem 2007a;14:201-207.

Li, L.; Chen, P.; Glkoyna, E. F. AIChE J. 37 (1991) 1687.

Lin, S.S., Chen, C.L., Chang, D.J., Chen, C.C. Water Res. 36 (2002) 3009.

Luck, F. Catal.Today 27(1996) 195

Luck, F., Catal. Today 53 (1999) 81.

Maleki A., Mahvi A.H., Vaezi F., Nabizadeh R. Iran J Environ Health Sci Eng 2005; 2(3):201206.

Mantzavinos, D.; Hellenbrand, R.; Livingston, A. G.; Metcalfe, I.S. Water Sci. Technol. 36 (1997) 109.

Marselli B., Garcia-Gomez J., Michaud P. A., Rodrigo M. A., Comninellis Ch., J. Electrochem. Soc., 2003, 150, D79-D83.

Mason T. J., Lorimer.J. P. Sonochemistry: Theory, applications and uses of ultrasound in chemistry. New York: Ellis Horwood Ltd.; 1988.

Matatov-Meytal, Yu. I., Sheintuch, M., Ind. Eng. Chem. Re. 37 (1998) 309.

Matthews R. W., J. Phys. Chem. 91 (1987) 3328.

Matthews R. W., Water Res. 25 (1991) 1169.

Memming R., Prog. Surf. Sci. 17 (1984) 7.

Mieluch J., Sadkowski A., Wild J., Zoltowski P., Przem. Chem., 1975, 54(9), 513-516.

Minh, D.P., Gallezot, P., Besson, M. Appl. Catal. B 63 (2006) 68.

Mishra, V. S., Mahajani, V.V., Joshi, J.B., Ind. Eng. Chem. Re. 34 (1995) 2.

Najjar, W., Ghorbel, A., Perathoner, S., Centi, G. Studies in Surface Science and Catalysis 158B (2005) 2009.

Nikolopoulus, A.N., Igglessi-Markopoulu, O., Papayannakos, N. Ultrasound Sonochemistry 13 (2006) 92.

Nilsson A., Ronlan A., Parker V. D.. J. Chem. Soc., Perkin Trans., 1973, 1, 2337-2345.

Okawa, K., Suzuki, K., Takeshita, T., Nakano, K. Journal of Hazardous Materials B127 (2005) 68.

Pamfilov A.V., Mazurkevich YaS. Pakhomova E.P., Kinet. Catal. (USSR) 10 (1969) 915.

Pankaj C., Viraraghavan T., Sci. Total Environ. 407 ( 2009 ) 2474-2492 
Papouchado L., Sandford R. W., Petrie G., Adams R. N.. J. Electroanal. Chem., 1975, 65, 275284.

Patria, L., Maugans, C., Ellis, C., Belkhodja, M., Cretenot, D., Luck, F., Copa, B. Advanced oxidation processes for water and wastewater treatment, Parsons, S., Ed., IWA Publishing, London, 2004, p247

Patterson, D. A.; Metcalfe, I. S.; Xiong, F.; Livingston, A. G. Ind. Eng. Chem. Res. 40(2001) 5517.

Pintar, A., Besson, M., Gallezot, P. Appl. Cat. B: Environ. 30 (2001) 123.

Pintar, A., Levec, J. Chem. Eng. Sci. 47 (1992) 2395.

Pintar, A., Levec, J. Ind. Eng. Chem. Res. 33 (1994) 3070.

Prasad, C. V. S., Joshi, J. B. Indian Chem. Eng., 29 (1987) 46.

Raffainer, I. I.; von Rohr, P. R. Ind. Eng. Chem. Res. 40 (2001) 1083.

Rajeshwar K., Iba'ñ ez J. G. , Swain G. M., J. Appl. Electrochem., 1994, 24, 1077-1091.

Rivas, F. J.; Kolaczkowski, S. T.; Beltran, F. J.; McLurgh, D. B. Chem. Eng. Sci. 53 (1998) 2575.

Robert, R.; Barbati, S.; Ricq, N.; Ambrosio, M. Water Res. 36 (2002) 4821.

Sakthivel S., Shankar M.V., Palanichamy M., Arabindoo B., Bahnemann D. Murugesan W., V., Water Res. 38 (2004) 3001-3008.

Salinaeo A., Emeline A.V., Zhao J., H. Hidaka, Ryabchuk V.K., Serpone N.. Pure Appl. Chem. 71 (1999) 321-335.

Scott, J. P., Ollis, D. F. Environ. Prog. 14 (2) (1995) 88.

Serpone N., J. Photochem. Photobiol. A: Chem. 104 (1997) 1-12.

Serpone N., Salinaro A., Pure Appl. Chem. 71 (1999) 303-320.

Silva, A.M.T., Castelo-Branco, I.M., Quinta-Ferreira, R.M., Levec, J. Chem. Eng. Sci. 58 (2003) 963.

Silva, A.M.T. Quinta-Ferreira, R.M. J. Levec, Ind. Eng. Chem. Res. 42(2003) 5099.

Simond O., Schaller V., Comninellis Ch., Electrochim. Acta, 1997, 42, 2009-2012.

Smith V., de Sucre, M.A. Sc. Thesis, University of British Columbia, (1979).

Sonnen, D. M.; Reiner, R. S.; Atalla, R. H.; Weinstock, I. A. Ind. Eng. Chem. Prod. Res. DeV. 36(1997) 4134.

Suslick K.S., Sci. Am. 1989;260:80-86.

Suslick K.S., Sonochemistry. Science 1990;247(3):1439-1445.

Tahar N. B., Savall A., J. Electrochem. Soc., 1998, 145, 3427-3434.

Teo K., Xu C., Yang C. Ultrason Sonochem 2001;8:241-246.

Treimer S. E., Feng J., Scholten M. D., Johnson D. C., Davenport A. J., J. Electrochem. Soc., 2001, 148, E459-E463.

Vajnhandl S., Marechal A.M. J Hazard Mater 2007;141:329-335

Vitt J. E., Johnson D. C., J. Electrochem. Soc., 1992, 139, 774-778.

Wagner C., Traud W, Z. Elektrochem. 44 (1938) 391-454.

Wagner C., Traud W, Z. Mansfeld F., Corrosion 62 (2006) 843-855.

Wakabayashi, T.; Okuwaki, A. Bull. Chem. Soc. Jpn. 61(1988) 4329.

Weavers L. K., Hoffmann M. R.. Environ Sci Technol 1998;32:3941-3947.

Yoneyama H., Toyoguchi Y., H. Tamura, J. Phys. Chem. 76 (1972) 3460. 
Zimmerman, F. J. Wet air oxidation of hazardous organics in wastewater. U.S. Patent No. 2,665,249, 1950. 


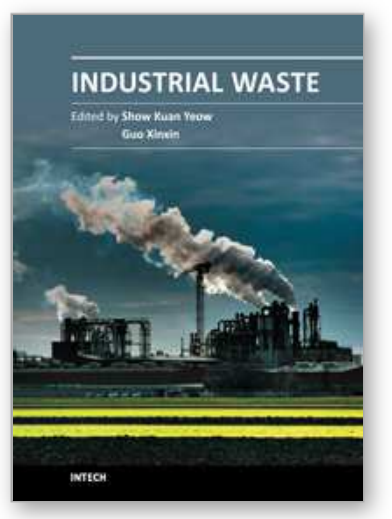

\author{
Industrial Waste \\ Edited by Prof. Kuan-Yeow Show
}

ISBN 978-953-51-0253-3

Hard cover, 274 pages

Publisher InTech

Published online 07, March, 2012

Published in print edition March, 2012

This book is intended to fulfil the need for state-of-the-art development on the industrial wastes from different types of industries. Most of the chapters are based upon the ongoing research, how the different types of wastes are most efficiently treated and minimized, technologies of wastes control and abatement, and how they are released to the environment and their associated impact. A few chapters provide updated review summarizing the status and prospects of industrial waste problems from different perspectives. The book is comprehensive and not limited to a partial discussion of industrial waste, so the readers are acquainted with the latest information and development in the area, where different aspects are considered. The user can find both introductory material and more specific material based on interests and problems. For additional questions or comments, the users are encouraged to contact the authors.

\title{
How to reference
}

In order to correctly reference this scholarly work, feel free to copy and paste the following:

Wei Liu, Dushu Huang, Ping Yi, Ying Li (2012). Status and Prospects of Concentrated Organic Wastewater Degradation, Industrial Waste, Prof. Kuan-Yeow Show (Ed.), ISBN: 978-953-51-0253-3, InTech, Available from: http://www.intechopen.com/books/industrial-waste/status-and-prospects-of-concentrated-organicwastewater-degradation

\section{INTECH}

open science | open minds

\author{
InTech Europe \\ University Campus STeP Ri \\ Slavka Krautzeka 83/A \\ 51000 Rijeka, Croatia \\ Phone: +385 (51) 770447 \\ Fax: +385 (51) 686166 \\ www.intechopen.com
}

\author{
InTech China \\ Unit 405, Office Block, Hotel Equatorial Shanghai \\ No.65, Yan An Road (West), Shanghai, 200040, China \\ 中国上海市延安西路65号上海国际贵都大饭店办公楼 405 单元 \\ Phone: +86-21-62489820 \\ Fax: $+86-21-62489821$
}


(C) 2012 The Author(s). Licensee IntechOpen. This is an open access article distributed under the terms of the Creative Commons Attribution 3.0 License, which permits unrestricted use, distribution, and reproduction in any medium, provided the original work is properly cited. 